\section{Tibia Kemiğine Ait Metrik Ölçümlerde Bilateral Asimetrinin Değerlendirilmesi}

\section{Öznur Gülhan ${ }^{1 *} \odot$}

${ }^{1}$ Arş. Gör. Dr. | Ankara Üniversitesi, Dil ve Tarih - Coğrafya Fakültesi, Antropoloji Bölümü, Ankara / TÜRKiYE
ARAŞTIRMA MAKALESI / RESEARCH ARTICLE

\section{Öz}

Biyolojik profil oluşturmak hem biyoarkeolojide hem de adlî antropolojide iskelet kalıntılarının tanımlanmasında oldukça önemli bir parametredir. Ayrıca, biyolojik profil belirlenirken tercih edilen tekniklerin, uygulanan popülasyon için güvenilir olması sonuçların doğruluk oranını oldukça etkilemektedir. Bilateral asimetri, insan vücudunun sağ ve sol taraflarının ölçümleri arasındaki fark olarak tanımlanmakta ve kemik büyümesi sırasında kemiklerin maruz kaldığı mekanik gerileme ve şekil değiştirmeye tepki olarak üst ve alt ekstremitelerin boyutlarında yönel asimetri gözlenebilmektedir. Özellikle adlî antropoloji vaka çalışmalarında iskelet materyalden biyolojik profil oluşturulurken kemiklerde bulunabilecek bilateral varyasyonlar hatalı tahminlere neden olabilmektedir. Bu sebeple, bu kemikler arasında bilateral asimetrinin varlı̆̆ı, kullanılan yöntemlerde dikkate alınmaz ise çıkan sonuçlar özellikle mediko-yasal araştırmalarda yarardan çok zarara sebep olabilir. Tibia, boy uzunluğu ve cinsiyet tahmininde sıklıkla tercih edilen kemiklerden bir tanesidir. Bundan dolayı, sağ ve sol taraflar arasındaki potansiyel farklılıklar nedeniyle biyolojik profil oluşturmaya yardımcı yöntemlerde kullanmadan önce bilateral asimetri düzeyinin araştırılması gerekmektedir. Bu çalışmanın amacı, tibiadaki bilateral asimetrinin varlığını araştırmak ve cinsiyetler arası farklılıkları incelemektir. Bu sebeple, kemik patolojisi olmayan 32 yetişkin bireyin bilgisayarlı tomografi taramalarından elde edilen tibia görüntüleri araştırmada kullanılmıştır. OsiriX programının hacimsel görüntüleme modu kullanılarak işlenen $3 \mathrm{~B}$ tibia görüntülerinden dört adet metrik ölçüm manuel olarak alınmıştır. Bilateral asimetri ile ilgili istatistiksel sonuçlara göre, Türk popülasyonundan alınan 32 bireye ait tibia ölçümlerinin birçoğunun sol tarafa eğilimlilik gösterdiği gözlenmekle birlikte, her iki cinsiyette iki taraf arasında istatistiksel olarak anlaml bir fark bulunmamıştır. Ayrıca, MTL'nin mutlak asimetri yüzde değeri dışında hem \%AA hem de \%DA değerleri için cinsiyetler arası anlamlı bir fark bulunmamıştır.

Anahtar Sözcükler: Bilateral asimetri, tibia, metrik ölçüm, biyolojik profil, yönel asimetri

\section{Giriş}

Antropoloji araştırmalarında biyolojik profil belirleme, bir iskelet çalışmasında ilk araştırılan parametrelerden biridir. Özellikle adlî vakalarda, bireyin kimliğinin tanımlanması adlî soruşturmalarda temel bir amaçtır.

\section{Evaluation of Bilateral Asymmetry in Metric Measurements on Tibiae}

\section{Abstract}

Creating a biological profile is an important parameter in the identification of skeletal remains in both bioarchaeology and forensic anthropology. In addition, the reliability of the preferred techniques when determining the biological profile affects the accuracy of the results. Bilateral asymmetry is defined as the difference between the measurements of the right and left sides of the human body, and directional asymmetry can be observed in the dimensions of the upper and lower extremities in response to mechanical regression and deformation during bone growth. Especially in forensic anthropological case studies, bilateral variations that can be found in bones while creating a biological profile from skeletal material can cause erroneous predictions. For this reason, if the presence of bilateral asymmetry between these bones is not considered while applying these methods into research, the results may cause erroneous results especially in medico-legal researches. Therefore, it is necessary to investigate the level of bilateral asymmetry before using this bone in methods to create biological profiles due to potential differences between the right and left sides. The aim of this study is to investigate the presence of bilateral asymmetry in the tibia and to examine the differences between the sex. Therefore, tibia images obtained from computerized tomography scans of 32 adult individuals without bone pathology were used in the study. Four metric measurements were taken manually from 3D tibia images processed using the Volume Rendering mode in OsiriX software. According to the statistical results related to bilateral asymmetry, it was observed that most of the tibia measurements taken from the Turkish population showed tendency to the left, but there was no statistically significant difference between the two sides in both sexes. Moreover, apart from the absolute asymmetry percentage value of MTL, there was no significant sex difference for both\% $A A$ and $\% D A$ values.

Key Words: Bilateral asymmetry, tibia, metric measurements, biological profile, directional asymmetry

Tanımlanamayan iskelet kalıntılarından yaş, cinsiyet ve boy uzunluğu ve atasal köken tahminlerini içeren biyolojik bir profilin oluşturulması diğer osteolojik verilerle birleştirildiğinde kritik kişisel bilgilerin toplanmasiyla potansiyel kimlik havuzunu daraltarak, 
DNA veya dental kayıtların kullanılmasına ve böylece pozitif bir kimliklendirmenin yapılmasına yardımc1 olabilir. $\mathrm{Bu}$ nedenle, belirlenen biyolojik profilin doğruluğu ve hassasiyeti çalışılan kalıntıların doğru bir şekilde tanımlanıp tanımlanmamasını doğrudan etkileyebilmektedir (Gülhan, 2018; Howley vd., 2018; Stoyanova vd., 2019).

İnsan iskelet kalıntılarından biyolojik profil, metrik ve metrik olmayan yöntemler olmak üzere iki kategoride yapılabilmektedir. Metrik yöntemler, landmark, semi-landmarklara dayalı osteometrik ölçümlerin toplanmasını ve analizini içerirken; metrik olmayan yöntemler morfolojik özelliklerin görsel değerlendirmesine dayanmaktadır. Osteometrik landmarkların çoğu durumda homojen olarak iyi bir şekilde tanımlanabilmesinden dolayı metrik yöntemlerin genellikle daha objektif olduğu düşünülür ve bu sebeple daha çok tercih edilmektedir. Yalnız bu durumun da kendi içerisinde sınırlılıkları vardır. Bir landmark ne kadar iyi tanımlanmış olsa da, her zaman aynı şekilde işaretlenmesinin kolay olmadığ1 durumlar da olabilmektedir. Bu sebeple, araştırmalarda güvenilir ve tekrarlanabilir metrik ölçümleri tercih etmek önemlidir (Lesciotto, 2015; Tersigni-Tarrant ve Shirley, 2013). Yapılan bu çalışmalar aynı zamanda belirlenen metrik standartların yüksek oranda popülasyona özgü olduğunu açıkça göstermiştir. Özellikle son yıllarda, popülasyona özgü standartlar adlî antropolojik çalışmalarda da oldukça ilgi çeken bir konu olarak kendini göstermektedir (İşcan, 2005). Bu nedenle çoğu akademisyen, medikoyasal uygulamalar için güncel teknikler veya verilerle daha doğru bilgi sağlamaya çalişan popülasyona özgü çalışmalara odaklanmıştır. (Dirkmaat, 2014).

Ayrıca, bazı araştırmalar biyolojik profil çıkarılırken kullanılan yöntemlerde kemiklerde olabilecek bilateral asimetri düzeylerine dikkat edilmesi ve yöntemlerin buna göre uygulanması gerektiğini belirtmişlerdir (Krishan vd., 2010; Lottering vd., 2013). Bilateral asimetri, insan vücudunun sol ve sağ taraflarının ölçümleri arasındaki fark olarak tanımlanmaktadır (Nandi vd., 2018). Belirli iskelet elementleri, vücudun sağ ve sol tarafları arasında boyut ve/veya şekil farklılıkları yaratarak çevresel, hormonal, biyomekanik ve genetik faktörlerden farklı şekilde etkilenmektedirler (Ruff ve Jones, 1981; Steele ve Mays, 1995; Auerbach ve Ruff, 2006; Auerbach ve Raxter, 2008; Kanchan vd., 2008; Kujanová vd., 2008; Krishan vd., 2010; Kirchengast, 2017). Bir özelliğin bir tarafta diğerinden daha fazla gelişmesi eğilimi olduğunda buna yönel asimetri denir (Chovalopoulou vd., 2017). Sonuç olarak, yönel asimetriden etkilenen bir özelliğin frekans dağılımları, sağ veya sol taraftan bir tanesinin daha fazla etkilendiği yere bağlı olarak, pozitif veya negatif olarak eğrilir ve diğer asimetrilerden önemli ölçüde farklı olan popülasyon düzeyinde sapmalar olarak tanımlanır (Auerbach ve Raxter, 2008). Insanlar kontralateral uzuvlar arasındaki çapraz simetriye bağlı olarak benzersiz bir türdür, yani vücudun bir bölgesi bir tarafa yönel asimetri gösterirken, başka bir bölge karşı tarafa yönel asimetri gösterebilir. İnsanların üst ekstremite boyutunda, sağ tarafa doğru büyük bir yönel asimetri ve alt ekstremitede sol tarafa doğru daha küçük bir yönel asimetri vardır (Schaeffer 1928; Latimer ve Lowrance 1965; Ruff ve Jones 1981; McGrew ve Marchant 1997; Plochocki 2004). İnsan iskeletindeki kemiklerin sağ ve sol taraflarında bulunan asimetriler bir asırdan fazla süredir araştırılmış ve bu çalışmalar, yaşayan bireyler, arkeolojik örnekler veya kadavralar gibi farklı örneklemler üzerinde yapılmıştır. Ancak bunlar, genellikle postkraniyal iskeletteki extremitelerin toplam uzunlukları ve ağırlıklarına odaklanmıştır (Ruff ve Jones, 1981; Auerbach ve Raxter, 2008).

İskelette asimetri ile ilgili erken çalışmalardan biri, Arnold tarafindan 1844 yllında femur üzerinde yapılmış ve bu çalışmanın sonucunda femur kemiğinde sol tarafin daha baskın olduğu bulunmuştur (Stirland, 1993). 1879 yllinda Garson tarafindan 70 iskeletin alt ekstremitesi üzerinde yapılan başka bir çalışmada ise, vakaların \%54,5'inde sol femur kemiği sağ femurdan daha uzun bulunmuştur (Garson, 1879). 1897 yllinda Warren'ın 114 birey üzerinde yaptığ çalışmaya göre femur ölçümlerinde anlamlı bir fark olmadığı, bir asimetri gözlenmediği sonucuna varılmıştır (Warren, 1897). Benzer sonuçlar Pearson ve Bell (1919) ile Trotter ve Gleser (1952) tarafindan tekrarlanmıştır. Yakın tarihli bir çalışmada Krishan ve arkadaşları (2010), Kuzey Hindistan da endogamous bir grup olan Gujjars toplumunda sağ elini kullanmayı tercih eden 967 yetişkin bireyin üst ve alt ekstremitelerinden aldıkları altı ölçümü incelemiş ve bu kemiklerde asimetri olduğunu gözlemlemiştir. Pierre ve arkadaşları (2010) tıbbi görüntüleme teknikleriyle elde edilen 20 çift kadavra üzerinde yapmış oldukları çalışmada, sağ ve sol femur arasında anlamlı bir bilateral varyasyon bulamamışlardır. Eckhoff ve arkadasslarinın (2016) femur ve tibia kemiğinin sağ ve sol taraflarının 3 boyutlu morfolojik karşılaştırmasını yaptıkları araştırmada, bu kemiklerde bilateral asimetri olduğunu, özellikle cerrahların alt ekstremite rekonstrüksiyonlarında simetri sağlamaya çalışmamaları gerektiğini ve var olan asimetri düzeyini göz önünde bulundurmaları gerektiği sonucuna varmışlardır.

Yukarıdaki çalışmalardan anlaşılacağı üzere farklı kemikler üzerinde yapilan bilateral asimetri düzeyi hakkında farklı sonuçlara ulaşılmıştır. Özellikle alt ekstremite kemiklerindeki asimetri düzeyinin çalışmalarda hesaba katılıp katılmaması gerektiği ile ilgili farklı görüşler vardır.

Her ne kadar yapılan tüm bu çalışmalar, çeşitli 
çevresel koşullar altında yaşayan farklı gruplardan elde edilmiş olsa da, bu çalışmaların birçoğu kemiklerde belli seviyede bilateral asimetri gözlendiğini ve üst ekstremite kemiklerinin uzunluk ve ağırlık olarak alt ekstremite kemiklerine göre daha yüksek düzeyde bilateral asimetri gösterdiği sonucunu elde etmişlerdir (Ruff ve Jones, 1981). Spesifik olarak, üst ekstremitelerdeki kemiklerin el baskınlığına bakılmaksızın, sağ taraftaki kemiklerin daha uzun ve daha geniş olduğu, bu durumun da muhtemelen sağ elini kullanan kişilerin sayısının fazlalığ1 ve artan mekanik yükün bir sonucu olarak açıklanabilir (Hildebrandt vd., 2016). Başka bir açıklamada ise, çoğu insanın "sağ ayaklı" olmasından dolayı sağ ekstremitelerin üzerinde daha fazla motor kontrolüne sahip olduğu, bir başka deyişle, sol tarafın daha çok dengeleyici görevi gördüğ̈̈, sağ tarafin ise "manipülatif" aktivite amacıyla kullanıldığı, bundan dolayı da uzuvlarda hafif sol taraflı bir asimetrinin geliştirildiği belirtilmektedir (Auerbach ve Ruff, 2006; Sládek vd., 2017). Tekme gibi görevleri yerine getirirken dominant olmayan bacağın biyomekanik olarak yüklenmesine ek olarak, el becerisi ve alt bacak nöron uyarılabilirliği arasındaki ters ilişkiden kaynaklandığı varsayılmaktadır (Hildebrandt vd., 2016). Özellikle sporcular üzerinde yapılan çalışmalar neticesinde çevresel (genellikle aktivite ile ilgili) faktörlerin asimetri ile olan ilişkileri açıklansa da insan vücudunda gözlenen her asimetri çevresel etmenlerle açıklanamamaktadır. Schultz, 1926 yılında insan fetüsleri üzerinde yaptı̆̆ çalışmada dört aylık fetüslerin femur ve ayak uzunluklarında asimetri gözlemiş ve bu durumun aktiviteye bağlı önemli stres faktörlerinden çok önce etkili olduğunu bulmuştur (Ruff ve Jones, 1981). Buna benzer çalışmalar literatürde oldukça fazladır ve asimetrinin hangi bireylerde daha fazla gözlendiği ve asimetriye sebep olabilecek aktivitelerin neler olduğu üzerine yapılan araştırmalarda, genellikle çalışlan örneklem profesyonel sporcular ya da fiziksel iş gücü gerektiren iş kollarında yaşayan bireyler gibi seçilmiş gruplara yoğunlaşılmıştır. Bu sebeple, sistematik olarak araştırılmamış ya da seçilmemiş "normal" bir grup üzerinde hangi kemiklerin popülasyonda bilateral asimetri gösterdiği ile ilgili çalışmalar oldukça azdır ve en önemlisi bilateral asimetri gözlemlenen kemiklerin antropolojide kullanılan yaş, cinsiyet, boy uzunluğu tahmini için kullanılan formül ve standartlarda ne gibi etkileri olabileceği çok detaylı araştırılmamıştır. Özellikle biyolojik profil belirleme ya da toplu halde birbiriyle karışış durumda bulunan iskelet gruplarını birbirinden ayırmaya çalışırken sağ ve sol kemiklerin birbiriyle ilişkisinin rastgele tanımlanması ya da kemiğin hangi tarafa ait olduğunun belirlenmeden çalışılması hatalı bir sonuca ulaşılmasına sebebiyet verebilmektedir. $\mathrm{Bu}$ sebeple, popülasyona özgü bilateral asimetri düzeyinin araştırılması ve gerekli olduğu durumlarda kullanılması oldukça önemlidir.

Daha önceki çalışmalar tibiadan alınan metrik ölçümlerin seksüel dimorfizm gösterdiğini ve cinsiyet (Holland, 1991; Kieser vd., 1992; Steyn ve İşcan, 1997; Gonzaléz-Reimers vd., 2000; Robinson ve Bidmos, 2011; Šlaus vd., 2013) ve boy uzunluğu Jantz vd., 1995; Hishmat vd., 2015; Ugochukwu vd., 2016) ile tibia ölçümleri arasında güçlü bir korelasyon olduğunu göstermiştir. Bu nedenle, özellikle belirli bir popülasyon için yeni oluşturulmuş standartlar, sadece tibia ölçümleri kullanılarak güvenilir cinsiyet veya boy uzunluğu değerlendirmeleri sunabilir ve bu standartlar o popülasyona ait felaket kurbanlarının tanımlanması $(D V I)$, adlî vakalar ve biyoarkeolojik materyaller için kullanilabilir.

$\mathrm{Bu}$ makalede asimetri ifadesinin önemi, sağ ve sol tibia için özellikle biyolojik profil tanımlamasında kullanılan fonksiyonlarda ayrı denklemlere veya sağ ve sol tarafa özel modellere gerek olup olmadığına odaklanmaktadır. Bu sebeple, bu çalışmanın amacı Türk popülasyonuna ait 32 bireyin $3 \mathrm{~B}$ tibia görüntülerinden alınan dört metrik ölçüm kullanılarak bu kemikte bilateral asimetri gözlenip gözlenmediğini incelemektir.

\section{Gereç ve Yöntem \\ Veri kaynakları ve veri toplama}

Bu çalışmada, 2011-2014 y1lları arasında Türkiye'deki büyük eğitim ve araştırma hastanelerinden birinin radyoloji bölümünde 256 dilimli çift kaynaklı bilgisayarlı tomografi tarayıc1si (SOMOTOM Definition Flash, Siemens Medical Solutions, Forcheim, Almanya) kullanılarak çekilen tibia görüntüleri kullanılmıştır.

$\mathrm{Bu}$ çalş̧manın veri seti, 32 bireyden elde edilen 3 boyutlu tibia modellerinden oluşmaktadır. Tibia modelleri, BT anjiyografisi geçiren yetişkin bireylerin klinik anonimleştirilmiş BT tarama sekanslarından temin edilmiştir. Bu çalışmaya, herhangi bir yaralanma belirtisi ve patolojisi olmayan normal bireylerin görüntüleri dâhil edilmiştir. Araştırmada kullanılan örneklemin cinsiyet ve yaşlara göre dağılımı Tablo 1'de gösterilmektedir.

Tablo 1. Tanımlayıc1 istatistik verileri. (Ort.: Ortalama, Min.: Minimum, Maks.: Maksimum, SS: Standart Sapma)

\begin{tabular}{ccccccc}
\hline & $\mathrm{N}$ & Ort. & Min. & Maks. & Medyan & SS \\
\hline Erkek & 16 & 48,68 & 30 & 69 & 49 & 11,35 \\
Kadin & 16 & 48,75 & 30 & 69 & 48,50 & 12,41 \\
\hline
\end{tabular}

\section{Morfometrik ölçümler}

Çalışmada kullanılan 32 bireye ait tibia görüntüsü, BT çıktılarının Tıpta Dijital Görüntüleme ve İletişim (DICOM) görüntü dizisinden sanal 3B modelleme kullanan yeniden yapılandırma yöntemleri kullanılarak 
oluşturulmuştur. Yeniden yapılandırılmış tibia kemik yüzeylerinin $3 \mathrm{~B}$ modelleri, özel yazılım OsiriX Lite (v.11.0.2) programının hacimsel görüntüleme (VR) modu aracillğ ile oluşturulmuştur. Sonrasında, hacimsel görüntüleme modu ile biçimlendirilen 3B tibia görüntüleri diğer kemiklerden manuel olarak ayrılmıştır. Her bir bireyin BT veri seti, OsiriX yazllımında açıldıktan sonra geleneksel ölçümlerin alınma kuralları göz önünde bulundurularak, manuel olarak belirlenen landmarklar sonrasında doğrusal (linear) ölçümler alınmıştır.

Çalışmada kullanılan dört metrik ölçümün tanımları Tablo 2'de verilmiştir. Ayrıca, 3B tibia görüntülerinden alınan MTL, MPEB, MDEB ve TMD ölçümleri Resim 1'de gösterilmiştir.

\section{Istatistik}

Bu çalışmada bilateral asimetrinin varlığını araştırmak için kullanılan ilk istatiksel yöntem Student's t-test'tir. Ardından, her iki cinsiyet için ortalama sağ ve sol değerlerin karşılaştırılması grafik gösterim kullanılarak sunulmuştur. Çalışmada kullanılan metrik ölçümlerin güvenilirliğini ve hassasiyetini test etmek için 32 bireyin sağ ve sol tibia görüntüleri iki kez ölçülmüş ve ICC, TEM, \%TEM ve R kullanılarak analiz edilmiştir.

TEM değeri aşağıdaki formül kullanılarak hesaplanmıştır:

$$
T E M=\sqrt{\frac{\left(\sum D^{2}\right)}{2 N}}
$$
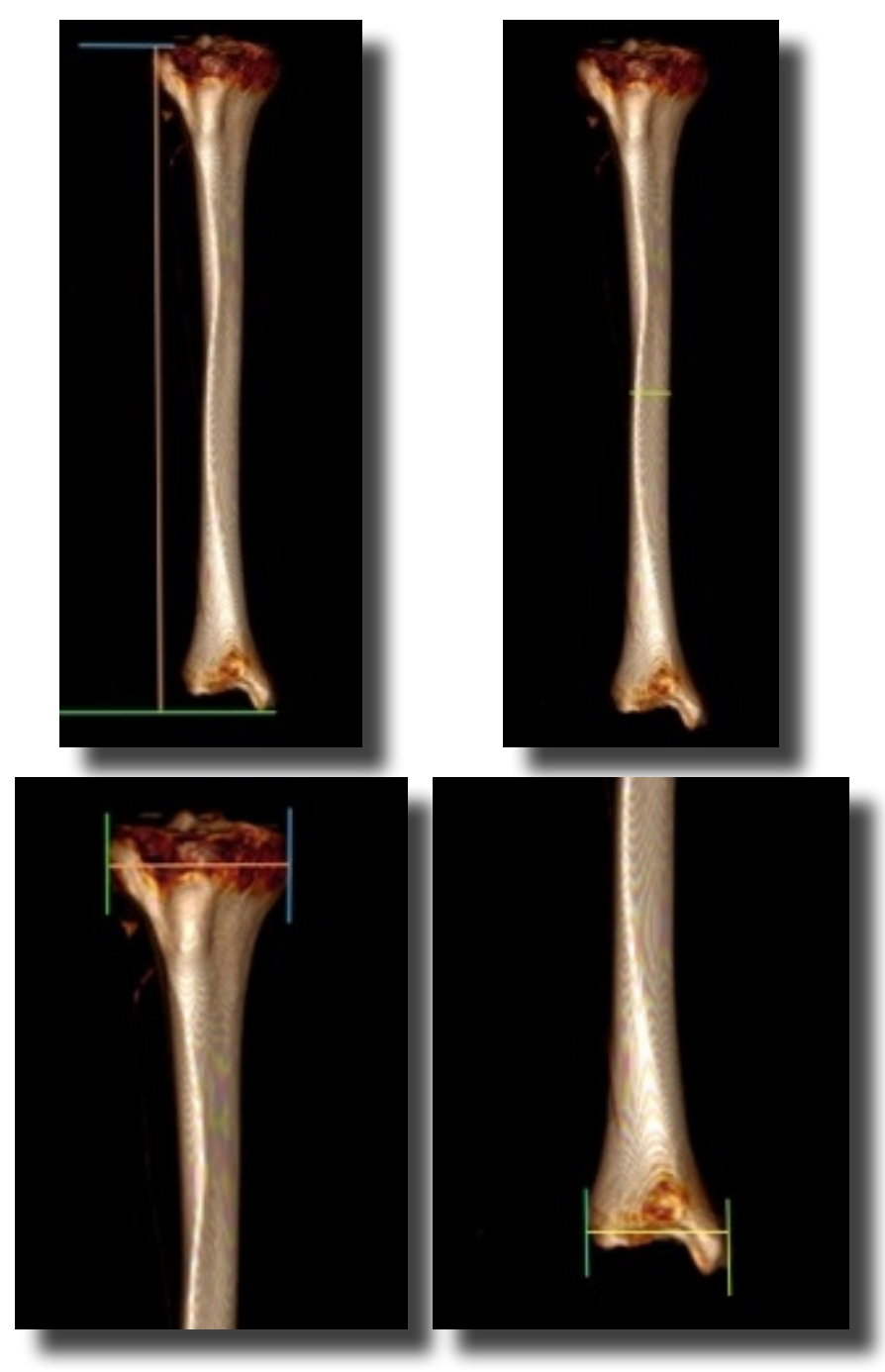

Resim 1. Hacimsel görüntüleme modu kullanılarak alınan tibia ölçümleri. Saat yönüyle sırayla MTL, TMD, MPEB ve MDEB.

Tablo 2. Çalışmada kullanılan tibia ölçümlerinin tanımlamaları ve kısaltmaları

\begin{tabular}{ccc}
\hline Ölçümler & Kisaltmalar & Tanımlar \\
\hline Tibia uzunluğu & MTL* & Lateral konilin eklem yüzeyinin en üst kısmı ile medial malleolusun en alt noktası \\
arasındaki uzunluk
\end{tabular}

Tibia maksimum proksimal epifiz genişliği

Tibia maksimum distal epifiz genişliği

Tibia mediolateral gövde genişliği

TMD

TPL **
Tibia platosunun en geniş (yanlarda en fazla çıkıntı yapan) noktaları arasındaki maksimum uzunluk

Medial malleolusdaki en medial noktası ile distal epifizdeki en lateral nokta arasindaki maksimum mesafe

Tibia gövdesinin ortasından alınan maksimum genişlik 
Formülde belirtilen D, ölçümler arasındaki farkı ve $\mathrm{N}$ ise ölçülen toplam örneklem sayısını ifade etmektedir. Mutlak TEM, aşağıdaki denklem kullanılarak göreli TEM'e (\%TEM) dönüştürülmüştür:

$$
\% T E M=\left(\frac{T E M}{\text { mean }}\right) \times 100
$$

Buradaki ortalama değer, gerçekte ölçülen tüm parametrelerin ortalamasını ifade etmektedir (Stomfai vd., 2011).

Katsayı güvenilirliği (R), ölçüm hatası olmayan bir popülasyondaki varyansin bir tahmininin elde edilmesini sağlamaktadır. Güvenilirlik puanlarının katsayısı 0 ila 1 arasında değişmektedir. Değerler, 0’a yaklaştıkça ölçüm hatası artmakta yani örneklemler arasındaki tüm varyasyonun ölçüm hatasının sonucu olduğunu gösterirken, 1'e yaklaştıkça ölçüm hatası olmadığını göstermektedir. R genellikle yüzde olarak ifade edilir.

Katsayı güvenilirliği (\% R) aşağıdaki denklem kullanılarak hesaplanmıştır:

$$
R \%=1-\left(\frac{T E M^{2}}{S D^{2}}\right)
$$

Son olarak, sağ ve sol tibia kemiğinde bilateral asimetri olup olmadığını değerlendirmek için Yönel Asimetri yüzdesi $(\% \mathrm{DA})$ ve mutlak asimetri yüzdesi $(\% \mathrm{AA})$ incelenmiştir.

Yönel asimetri yüzdesi $(\% \mathrm{DA})$, genellikle kemiğin sağ ve sol tarafları arasındaki farklılıkları karşılaştırmak için kullanılan bir yöntemdir (Steele ve Mays, 1995). $\% \mathrm{DA}$ asimetri değeri, ham asimetri farklılıklarını taraflar içindeki yönel asimetri yüzdesine göre standartlaştırarak farklı değişkenlerin boyutlarındaki asimetrinin doğrudan karşılaştırılmasına olanak sağlar. Kısaca, belirli bir boyutta bulunan yönel asimetri miktarını açıklar. Yönel asimetri yüzdesi pozitif olan değerler, sağ taraftaki değişkenlerin sol taraftaki değişkenlerden daha yüksek olması (sağa eğilimli asimetrileri); negatif değerler ise sol taraftaki değişkenlerin sağ taraftan daha büyük değerlere sahip olduğunu (sola eğilimli asimetrileri) ifade eder. (Auerbach ve Raxter, 2008). \%DA, aşağıda verilen formül kullanılarak hesaplanmıştır (Steele ve Mays, 1995; Auerbach ve Ruff, 2006):

$$
\% D A=\frac{\text { Sa } \breve{\mathrm{g}}(\text { Right })-\text { Sol }(\text { Left })}{\text { Sağ ve Sol Ortalamasl }} \times 100
$$

Sapma (bias) dikkate alınmadan mevcut toplam asimetri miktarını değerlendirmek için her değişkenin mutlak asimetri yüzdesi (\%AA)'de hesaplanmıştır. Temel olarak, \%AA değisskenlerde ne kadar yönel asimetrinin ortaya çıktığını ifade eder. (\%AA) verilen şu denklem kullanılarak hesaplanmıştır (Steele ve Mays, 1995; Auerbach ve Ruff, 2006):

$$
\% A A=\frac{(\text { Maksimum }- \text { Minimum })}{\text { Maksimum and Minimum Ortalamasl }} \times 100
$$

\%DA'nın araştırılması, baskın yönel asimetri sapmasını ve bu sapmanın büyüklüğünü ortaya çıarırken, \%AA'nın hesaplanması yönel sapmaya bakılmaksızın belirli bir boyutta ne kadar yönel asimetri oluştuğunu gösterir (Auerbach ve Raxter, 2008).

Son olarak, her iki cinsiyet arasinda $\% \mathrm{DA}$ ve $\% \mathrm{AA}$ değerleri açısından bir fark olup olmadığını belirlemek için Mann-Whitney U testi kullanılmıştır.

\section{Bulgular}

İlk önce değişkenlerin normal bir dağılım sağlayıp sağlamadığını test etmek için Shapiro-Wilk testi uygulanmış ve bu analiz sonucunda tüm değişkenlerin her cinsiyette normal dağılım sergilediği gözlenmiştir. Daha sonra sağ ve sol tibia kemiğinden alınan ölçümler arasında karşılaştırma yapmak ve bilateral asimetri düzeyinin varlığını incelemek için Student t-testi kullanılmıştır (Tablo 3). Farklı modern insan örneklerinin kullanıldığ1 bazı araştırmalarda bilateral asimetrinin cinsiyete göre değiştiği bildirildiği için (Ruff ve Jones, 1981; Auerbach ve Ruff, 2006), bilateral asimetriyi hesaplarken t-testi hem erkek hem de kadın örnekler için ayrı ayrı uygulanmıştır. $\mathrm{p}<0,05$ değeri istatistiksel olarak anlaml kabul edilmiştir.

Tablo 3'te gösterilen paired t-testinin sonuçlarına göre, kadın ve erkek örneklerden alınan her dört ölçüm için sağ ve sol tibia değerleri arasında istatistiksel olarak anlamlı bir fark (p>0,05) gözlenmemiştir.

Şekil 2'de her iki cinsiyet için tüm ölçümlerin ortalama să̆ ve sol değerleri arasındaki farklilıklar görülmektedir.

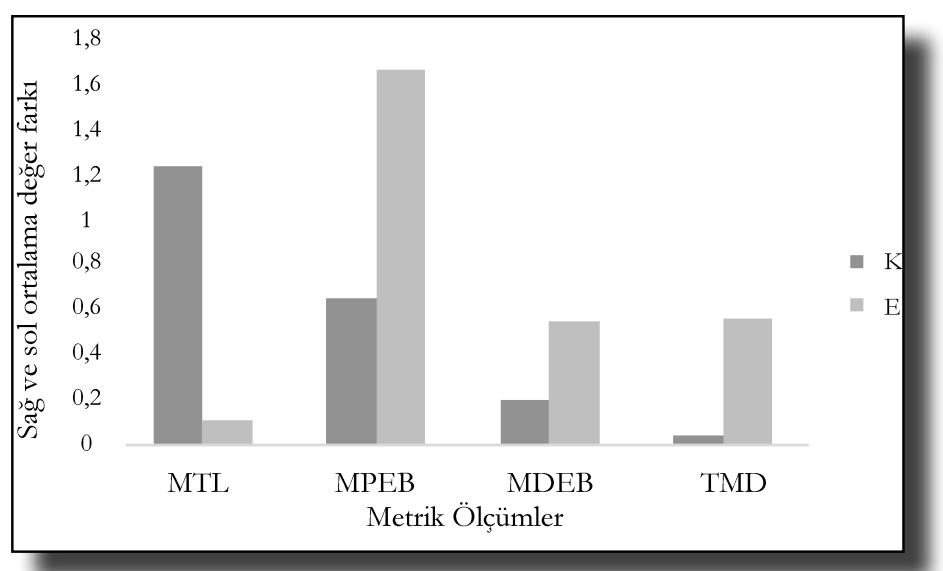

Resim 2. Tibia metrik ölçümlerinin ortalama sağ ve sol farkları

Tibianın proksimal epifizinden alınan MPEB ölçümünün sağ ve sol tarafları arasındaki fark, erkeklerde kadınlara göre daha yüksektir. Ayrıca aynı değişken, 
Tablo 3. Bilateral asimetri için Student t-test'i sonuçları

\begin{tabular}{|c|c|c|c|c|c|c|c|c|c|}
\hline \multirow{2}{*}{\multicolumn{2}{|c|}{ Ölçümler (mm) }} & \multicolumn{4}{|c|}{ Erkek $(n=16)$} & \multicolumn{4}{|c|}{$\operatorname{Kadin}(n=16)$} \\
\hline & & Ort. & SS & $t$ & $\mathrm{p}$ & Ort. & SS & $t$ & $\mathrm{p}$ \\
\hline \multirow{3}{*}{ MTL } & Sağ & 360,71 & 22,51 & \multirow{3}{*}{0,072} & \multirow{3}{*}{0,943} & 319,06 & 29,51 & \multirow{3}{*}{$-0,663$} & \multirow{3}{*}{0,943} \\
\hline & & & & & & & & & \\
\hline & Sol & 360,60 & 22,59 & & & 331,54 & 28,98 & & \\
\hline \multirow[b]{2}{*}{ MPEB } & Sağ & 77,00 & 4,04 & \multirow[b]{2}{*}{$-2,852$} & \multirow[b]{2}{*}{0,012} & 71,42 & 4,39 & \multirow[b]{2}{*}{-214} & \multirow[b]{2}{*}{0,012} \\
\hline & Sol & 78,65 & 2,88 & & & 72,06 & 3,55 & & \\
\hline \multirow[b]{2}{*}{ MDEB } & Sağ & 54,47 & 3,67 & \multirow[b]{2}{*}{$-0,994$} & \multirow[b]{2}{*}{0,336} & 49,88 & 4,11 & \multirow[b]{2}{*}{0,410} & \multirow[b]{2}{*}{0,33} \\
\hline & Sol & 55,01 & 3,05 & & & 49,99 & 3,96 & & \\
\hline \multirow{3}{*}{ TMD } & Sağ & 28,06 & 3,11 & \multirow{3}{*}{$-1,184$} & \multirow{3}{*}{0,255} & 22,26 & 2,72 & \multirow{3}{*}{0,926} & \multirow{3}{*}{0,25} \\
\hline & & & & & & & & & \\
\hline & Sol & 28,62 & 3,45 & & & 22,21 & 2,88 & & \\
\hline
\end{tabular}

Tablo 4. Sınıf içi korelasyon karşılaştırma katsayısı (2 tekrar) (n=16)

\begin{tabular}{|c|c|c|c|}
\hline Değişkenler & ICC & $(95 \% \mathrm{CI})$ & Cronbach's Alpha \\
\hline MTL & 0,998 & $(0,995-0,999)$ & 0,998 \\
\hline MPEB & 0,957 & $(0,877-0,985)$ & 0,957 \\
\hline MDEB & 0,935 & $(0,820-0,977)$ & 0,935 \\
\hline TMD & 0,962 & $(0,893-0,987)$ & 0,961 \\
\hline
\end{tabular}

Tablo 5. Güvenilirlik katsayısı (\%R), göreceli teknik ölçüm hatası (\%TEM) ve mutlak teknik ölçüm hatası (TEM) sonuçları

\begin{tabular}{ccccccc}
\hline Değişkenler & N & SS & Ortalama & TEM & \%TEM & R \\
\hline MTL & 16 & 24,77 & 353,21 & 1,52 & 0,43 & 0,99 \\
MPEB & 16 & 5,50 & 73,16 & 1,60 & 2,19 & 0,91 \\
MDEB & 16 & 3,90 & 49,64 & 1,38 & 2,78 & 0,87 \\
TMD & 16 & 4,03 & 26,19 & 1,10 & 4,23 & 0,92 \\
\hline
\end{tabular}

diğer üç değişkene nazaran sağ ve sol taraflar arasında erkeklerde en yüksek farka sahipken, kadinlarda en yüksek fark maksimum tibia boy uzunluğu olan MTL ölçümünde gözlenmektedir. Buna karşın, MTL değeri erkeklerde diğer üç değişkenle karşılaştırıldığında en az farka sahip olan değişkendir. MPEB, MDEB ve TMD değerleri arasındaki fark erkeklerde kadınlara göre daha yüksek, ancak MTL değerinin tarafları arasındaki fark kadınlarda (1,22 mm) daha yüksektir.

Araştırmada kullanılan istatistiklerin geçerliliğ̣i kullanılan ölçümlerin güvenilirliğine bağlıdır. Ölçüm hatasını test etmek için 16 bireyden alınan dört ölçüm, bir hafta ara ile iki kez tekrarlanmış ve ICC, TEM, \%TEM ve $\mathrm{R}$ istatistikleri ile analiz edilmiştir. Sınıf içi korelasyon (ICC) sonuçları Tablo 4'te gösterilmiştir.

ICC değeri 0'a yaklaştıkça tekrarlanan ölçümler arasındaki uyum azalmakta, 1'e yaklaştıkça artmaktadır (Steyn vd., 2012). Bununla birlikte 0,90'dan büyük ICC değerleri yüksek güvenilirliği ifade etmektedir (Koo ve Li, 2016). Gözlemci içi hata değerlendirilmesinde, kaydedilen ilk ölçüm ile ikinci ölçüm arasındaki ICC değeri tüm değişkenler için 0,935 ile 0,998 arasında 
Tablo 6. Cinsiyetlere göre ve tüm örneklem için ortalama ve medyan \%DA ve \%AA değerleri

\begin{tabular}{|c|c|c|c|c|c|c|}
\hline \multirow{2}{*}{$\begin{array}{c}\text { Ölçümler } \\
\text { (mm) }\end{array}$} & \multicolumn{3}{|c|}{ Medyan \%DA (ort. \%DA) } & \multicolumn{3}{|c|}{ Medyan \%AA (ort. \%AA) } \\
\hline & Toplam & Erkek $(n=16)$ & Kadın $(n=16)$ & Toplam & Erkek $(n=16)$ & $\operatorname{Kad} ı n(n=16)$ \\
\hline MTL & $-0,40(-0,17)$ & $-0,74(0,03)$ & $-0,12(-0,38)$ & $1,03(1,22)$ & $1,41(1,52)$ & $0,54(0,91)$ \\
\hline MPEB & $-1,93(-1,57)$ & $-2,36(-2,18)$ & $-0,78(-0,96)$ & $3,39(3,33)$ & $3,27(3,11)$ & $3,78(3,54)$ \\
\hline MDEB & $-0,84(-0,65)$ & $-1,30(-1,05)$ & $-0,52(-0,24)$ & $2,42(3,16)$ & $2,34(3,21)$ & $2,44(3,12)$ \\
\hline TMD & $-1,34(-0,79)$ & $-1,96(-1,86)$ & $1,29(0,27)$ & $6,57(6,29)$ & $5,15(5,67)$ & $6,95(6,91)$ \\
\hline
\end{tabular}

bulunmuştur. Bu değerlere göre, kullanılan dört metrik ölçümün sınıf içi korelasyon katsayısı sonuçlarına göre gözlemci içi güvenilirliğinin yüksek olduğu söylenebilir.

Gözlemci içi hatayı ve ölçüm hassasiyetini değerlendirmek için ayrıca her değissken için ölçüm teknik hatası (TEM), göreli ölçüm teknik hatası (rTEM) ve güvenilirlik katsayısı (R) hesaplanmıştır.

Tablo 5'e göre, TEM ve rTEM değerleri 1,10 ile 1,60 ve 4,23 ile 0,43 arasında değişmektedir. $\mathrm{Bu}$ TEM değerlerinin tümü, gözlemci içi hata için kabul edilebilir oranlardadır ve çalışmada kullanılan değişkenlerin tekrarlanabilir olduğunu göstermektedir. \%5’ten yüksek olan rTEM değerleri, hassas olmayan ölçümler olarak değerlendirilirken (Lottering vd., 2014), çalışmada kullanılan tüm değişkenlerin değerleri kabul edilir değerler içerisindedir. Dört ölçümün güvenilirlik katsayısı (R) karşılaştırıldığında, ölçüm hassasiyetinin en yüksek olduğu değişkenin MTL $(0,99)$ olduğu gözlenmiştir. 0,90'nın altındaki güvenilirlik katsayısına sahip ölçümler için kullanılırken dikkat edilmesi gerektiği bazı çalışmalarda belirtilirken (Torimitsu vd., 2015), çoğunlukla 0,75 'ten büyük değerlerin ölçümün hassas olduğunu gösterdiği kabul edilmektedir (Weinberg vd., 2005). Bununla birlikte, diğer üç değişkenin güvenilirlik katsayıları $(0,91,0,87$ ve 0,92$)$ kabul edilir değerler içerisindedir.

Her iki cinsiyete ait tibia ölçümlerinin yönel asimetri $(\% \mathrm{DA})$ ve mutlak yüzde asimetri $(\% \mathrm{AA})$ sonuçları Tablo 6'da sunulmaktadır.

Tablo 6'daki Medyan \%DA sonuçlara göre, kadınlarda TMD değeri dışındaki diğer üç değişkende sol taraflı bir eğilim (sol değerler sağdaki değerlerden daha yüksek) gözlenmiştir. Diğer taraftan, test edilen dört değişkenin hepsi erkeklerde sol taraflı bir eğilim sergilemektedir. Bununla birlikte, tüm değişkenlerde, erkeklerde kadınlara göre daha yüksek Medyan \%DA elde edilmiştir. Medyan \%AA değeri içinse, MTL değişkeni dışında diğer üç değişken için kadınlarda erkeklere nazaran daha yüksek değerler gözlenmektedir.

$\% \mathrm{DA}$ ve $\% \mathrm{AA}$ değerleri normal dağ 1 llmdan saptığ1 için parametrik olmayan istatistiki yöntemler kullanılmalıdır Jaskulska, 2009; Waidhofer ve Kirchengast, 2015). Bu sebeple, \%DA ve \%AA değerlerinin cinsiyetler arası farklılığını test etmek için t-testinin parametrik olmayan bir alternatifi olan Mann Whitney U testi kullanılmıştır. Tablo 7, \%DA ve \%AA için Mann Whitney U- testinin sonuçlarını göstermektedir. $\mathrm{p}$ $<0,05$ değeri istatistiksel olarak anlamlı kabul edilmiştir.

Tablo 7'de gösterilen Mann Whitney U testi sonuçlarına göre, kadın ve erkekler arasında yönel

Tablo 7. \%DA ve\%AA için Mann-Whitney U testinin sonuçları

\begin{tabular}{|c|c|c|c|c|c|c|}
\hline \multirow{2}{*}{$\begin{array}{l}\text { Ölçümler } \\
\text { (mm) }\end{array}$} & \multicolumn{3}{|c|}{$\% \mathrm{DA}$} & \multicolumn{3}{|c|}{$\%$ AA } \\
\hline & Mann-Whitney U & $\mathrm{Z}$ & $\begin{array}{c}\text { Anlamlilik } \\
\text { (2 kuyruklu) }\end{array}$ & Mann-Whitney U & $\mathbf{Z}$ & $\begin{array}{c}\text { Anlamlilık } \\
\text { (2 kuyruklu) }\end{array}$ \\
\hline MTL & 117,500 & $-0,396$ & 0,692 & 44,500 & $-3,147$ & 0,002 \\
\hline МРEB & 103,000 & $-0,942$ & 0,346 & 110,000 & $-0,678$ & , 0,497 \\
\hline MDEB & 117,000 & $-0,415$ & 0,678 & 126,000 & $-0,075$ & 0,940 \\
\hline TMD & 100,500 & $-1,037$ & 0,300 & 114,500 & $-0,509$ & 0,611 \\
\hline
\end{tabular}


asimetri (\%DA) ve mutlak asimetri yüzdesi (\%AA) için MPEB, MDEB ve TMD değişkenleri açısından anlamlı bir fark gözlenmemiştir. MTL değişkeni için ise kadın ve erkekler arasında \%AA değeri için istatistiksel olarak anlamlı bir fark $(p=0,002)$ vardır.

\section{Tartışma}

İskelette çift halde bulunan kemiklerin sağ ve sol tarafları arasındaki varyasyonlara asimetri dendiği yukarıda belirtilmiştir. Kemik üzerindeki gerilme veya mekanik stres nedeniyle alt veya üst ekstremitelerde bilateral varyasyonlar görülebilir. Bu durum bir taraftaki kemiğin üzerinde diğerine kıyasla daha büyük bir gelişmeye neden olabilir ve buna yönel asimetri denir (Kanchan vd., 2008).

Bilateral asimetri ile ilgili çalışmaların genellikle araştırdıkları konular, popülasyonlar arasındaki asimetri karşılaştırmaları ve iskelet popülasyonlarındaki çalışma koşulları ile ilgili bilgi toplamak için yapılmaktadır (Kubicka vd., 2016). Mevcut literatürde kemikler üzerinde bilateral asimetri oldukça fazla incelenmiş ve farklı sonuçlar elde edilmiştir. Özellikle alt ekstremitelerde bilateral asimetri çalışan araştırmaların bir kısmı istatiksel olarak anlamlı farklılıklar bulurken (Ruff ve Jones, 1981; Krishan vd., 2010; Hildebrandt vd., 2016), diğer çalışmalar istatistiksel olarak anlamlı bir fark olmadığını belirtmektedir (Kranioti ve Apostol, 2015; Ugochukwu vd., 2016).

Daha önce yapılmış çalışmalardan elde edilen veriler değerlendirildiğinde, insanlar arasındaki bilateral asimetri düzeyinin üst ekstremitelerde, alt ekstremitelere oranla daha belirgin olduğu sonucu ortaya çıkmaktadır (Auerbach ve Ruff, 2006; Kanchan vd., 2008; Kujanová vd., 2008; Fatah vd., 2012; Kubicka vd., 2016; Kurki, 2017). Önceki çalışmalar, sağ üst ekstremite kemiklerinin sol üst ekstremite kemiklerinden ortalama olarak daha uzun (yaklaşık \%1-3) ve daha ağır (yaklaş1k \%2-4); sol alt ekstremite kemiklerinin ise sağ alt ekstremite kemiklerinden ortalama olarak biraz daha uzun ve daha ağır (\%1'den daha az) olduğunu göstermiştir (Ruff ve Jones, 1981). İnsanlar arasındaki bilateral asimetri düzeyinin üst ekstremitelerde daha belirgin olmasının nedeni olarak gösterilen sebeplerden bir tanesi, üst ekstremitenin manipülasyonların lateral etkilerinden doğrudan etkilenmesidir. Ayrıca, bipadel hareketin neden olduğu alt ekstremitelerin nispeten simetrik yüklemesi, alt ekstremitelerin üst ekstremitelere nazaran daha az bilateral asimetri göstermesinin sebebi olarak gösterilebilmektedir (Sládek vd., 2017). Ayrıca çalışmalarda, üst ekstremitelerin să̆ baskınlığının olduğunu görülürken, alt ekstremitelerde ise tam tersi olarak sol baskınlık gözlenmektedir (Hildebrandt vd., 2016). Bununla birlikte, bilateral asimetrinin cinsiyetler arasında da farklılık gösterdiği bildirilmiştir (Fatah vd.,
2012; Waxenbaum ve Sirak, 2016).

Ruff ve Jones'in 1981 y1linda California'daki bir arkeolojik örnekte sağ ve sol tibia ile humerus kemiğinin A-P ve M-L radyografilerinden elde ettikleri kemik kesit genişlikleri ve alanları üzerine yaptıkları çalışmanın sonuçlarına göre, her iki kemikte de boyut ve şekil bakımından cinsiyet ve yaş grubuna göre değişiklik gösteren istatistiksel olarak anlamlı bilateral asimetri bulmuşlardır. Çalışmada, tibia kemiğinde gözlenen asimetri humerusa göre çok daha az belirgin ve sağ ve sol taraflar arasındaki tüm farklilıklar ortalama $\% 2$ veya daha az bulunmuştur. Sadece genç yetişkinler göz önüne alındığında, kadınlarda tibia kemik alanı asimetrisi \%3-4'e ulaşmaktadır. Ayrıca çalışmada, humerus boyutlarında (sağ taraf daha büyük) erkekler daha yüksek asimetri gösterirken, tibia boyutlarında (sol taraf daha büyük) kadınlarda daha yüksek bir asimetri gözlenmiştir (Ruff ve Jones, 1981). Bu çalışmada elde edilen bulgularda ise tüm değisskenler için erkeklerde kadınlara göre daha yüksek Medyan \%DA elde edilmiştir. Ancak, MTL'nin mutlak asimetri yüzde değeri dışında hem \%AA hem de \%DA değerleri için cinsiyetler arası anlamlı bir fark bulunmamıştır.

Arkeolojik ve çağdaş insan iskeletleri üzerinde yapılan çalışmalar, kemik uzunluklarının ve eklem yüzey boyutlarının asimetrik olduğunu, ancak diyafiz genişliklerinin bu değişkenlerden daha fazla asimetri gösterdiklerini belirlemişlerdir (Trinkaus vd., 1994; Auerbach ve Ruff, 2006). Örneğin, Trinkaus ve arkadaşlarının (1994), modern bir iskelet koleksiyonunda yapmış oldukları araştırmada alışılmış ve düzenli bir aktivite göstermeyen bireylerde humerus kemiğinin diyafiz genişliklerinde asimetriye rastlanmakla birlikte, tek taraflı aktiviteler gösteren atletlerde diyafiz boyutlarındaki asimetrinin daha büyük olduğunu bulmuşlardır. Mevcut çalışmada ise kadınlarda maksimum tibia boy uzunluğunu ölçmek için kullanılan MTL değeri sağ ve sol taraflar arasında en yüksek farka $(1,22 \mathrm{~mm})$ sahiptir. Buna rağmen, erkeklerde ise proksimal epifizden alınan MPEB ölçümünün sağ ve sol tarafları arasındaki fark $(1,65 \mathrm{~mm})$ en yüksek değeri göstermektedir. Diyafiz genişliğinden alınan TMD ölçümü kadınlarda en düşük farka $(0,04 \mathrm{~mm})$ sahipken, erkeklerde MPEB ölçümünden sonra en yüksek ikinci farka $(0,56 \mathrm{~mm})$ sahip değişkendir.

Antropoloji literatüründe üzerinde durulan konulardan biri de alt ekstremitelerden alınan metrik ölçümlerin arasında eğer bilateral asimetri gözlenirse, bu durumun cinsiyet ve boy uzunluğu tahmini gibi biyolojik profil oluşturmada kullanılan parametreleri nasıl etkilediği gelmektedir. Bilateral asimetrinin yaş, cinsiyet, atasal köken ve boy uzunluğu gibi değişkenlerin tanımlandığ1 biyolojik profil oluşturma sürecinde kullanılan teknikler üzerindeki etkisi daha önceki 
çalışmalarda araştırılmıştır (Krishan vd., 2010). Biyolojik asimetri, iskelet elementlerinin gelişme ve dejenerasyon sürecine farklı şekilde tanıklık etmeleri nedeniyle ortaya çıkabilir. Örneğin, yaş tahmini için kullanılan kemik özellikleri, olgunlaşma süresi ve çevresel faktörlerden etkilenebilir. Bu nedenle, uzamış bir olgunlaşma süresi ve oldukça değişken çevresel faktörlerin bir spektrumu, biyolojik asimetri için daha fazla olasılık sağlayarak iskelet kalıntılarından yapılan yaş tahminlerinin yanlış yorumlanmasina neden olabilir (Priya, 2017). Bu çalışmalardan biri Stoyanova ve arkadaşlarının (2019), 88 modern Amerikalı erkek bireye ait 3B lazer tarama yöntemi ile görüntüledikleri pubik simfizisde asimetri varllğ1 ve yaş tahminine etkisi hakkında yaptıkları araştırmadır. Yapılan çalışmanın neticesinde, pubik simfiziste herhangi bir yönel asimetri tespit edilmemiştir ve her iki tarafin morfolojik modelinin yaş tahmininde eşit derecede sonuç çıkardığı belirtilmiştir. Buna karşın, Lottering ve arkadaşlarının (2013), 195 Avustralyalı yetişkine ait $3 \mathrm{~B}$ pubik simfizis görüntüleri üzerinde yaptıkları çalışmada bilateral asimetri gözlemlemişlerdir. Bu sebeple, sağ ve sol yüzeye bağlı olarak yapılan yaş analizlerinde farklı yaş aralıklarının sergilenebileceğini öne sürmüssler ve mümkün olan her durumda her iki yüzeyden yaş tahmini yapılmasını önermişlerdir.

Bununla birlikte, aynı durum cinsiyet tahmini ve boy uzunluğu içinde geçerlidir. İskelet kalıntılarından boy uzunluğu hesaplanırken, insan vücudunun gösterdiği asimetri düzeyi sebebiyle, kemiklerin boyutlarında bulunan bilateral varyasyonlar nedeniyle hatalı tahminlere neden olabilirler (Krishan vd., 2010). Barnes ve arkadaşları 2019 yılında Tayland popülasyonuna ait karpal kemiklerden cinsiyet tahmini çalışması yapmıştır. Bu araştırmanın sonucunda karpal kemiklerden aldıkları 15 ölçümün 13 tanesinin asimetri gösterdiğini bulmuşlardır (Barnes vd., 2019). Aynı şekilde Doğa Tarihi müzesinde bulunan İsa Kilisesi, Spitalfields koleksiyonundan 100 bireyin karpal ölçümlerinden birçoğunda bilateral asimetri gözlenmiştir (Sulzmann, Buckberry ve Pastor, 2008). Buna karşın, Meksika (Mastrangelo, De Luca ve Sánchez-Mejorada, 2011) ve İspanya (Mastrangelo vd., 2011) örnekleri üzerinde yapılan çalışmalarda , sağ ve sol karpal kemikleri arasında istatistiksel olarak anlamlı bir fark bulunmamıştır. Bu çalışmalarda, Meksika ve İspanya örneklemleri için her iki taraf ölçümü cinsiyet tahmini için oluşturulan fomüllerde birlikte kullanilırken, Spitalfields örneklemi (Sulzmann vd., 2008) ve Tayland popülasyonu (Barnes vd., 2019) için her iki tarafa ait farklı formüller geliştirilmiştir. Başka çalışmalarda ise, örneklemlerinde bilateral asimetri seviyesinin az olduğunu bulsalar dahi, cinsiyet ve boy uzunluğu tahimini için oluşturdukları modelleri sağ ve sol taraflara özel olarak geliştirmektedirler (Howley vd., 2018). Ancak bu çalışmalarda oluşturulan modelleri kullanmak için önce kemiğin tarafinın belirlenmesi ve daha sonra bu taraf için geliştirilen uygun formülün uygulanmasi gerekmektedir.

Birbirine karışış halde bulunan kemiklerden birey ayrımı yapılırken, asimetrinin çift eşleştirme sürecinde karmaşık bir faktör olduğu bazı çalışmalarda bildirilmiş; özellikle standart metrik ölçümlerle ve ayrıca metrik olmayan yöntemleri kullanırken bu farkl1lı̆̆ın göz önünde bulundurulması gerektiği belirtilmiş ve problemi çözmeye yönelik yeni yöntemler geliştirilmeye çalış1lmıştır (Nikita ve Lahr, 2011). Bununla birlikte, antropologlar toplu halde birbirine karışmış şekilde bulunan insan iskeletleri üzerinde çalışmalar yaparken bilateral asimetri düzeylerini de düşünmeli ve eşleşen kemiklerde farkll1ık derecelerini göz önünde bulundurmalıdırlar (Lyman 2006). Bu konuyu gözden kaçıran bir araştırmacı, aslında aynı bireye ait iki eş kemik arasındaki şekil veya boyut farklılıklarından kaynaklı bu kemiklerin farklı bireylere ait olduğunu düşünebilir. Bilateral asimetrinin popülasyonlarda tam olarak anlaşılmaması, aynı bireye ait kemiklerin farklı bireyler olarak düşünülmesi veya bir çift kemiğin farklı bireyler ile ilişkilendirilebilmesine yol açabilir. Ayrıca, bazı araştırmalar popülasyonlar arasında extremitelerin uzunluğu ve ağırlığı bakımından farklı bilateral asimetri derecesine sahip olabildiklerini belgelemişlerdir (Trotter ve Gleser, 1952; Latimer ve Lowrance, 1965; Kanchan vd., 2008). Bu sebeple, bilateral asimetri düzeyinin her popülasyon için ayrıntılı bir şekilde araştırılması, antropolojik yöntemlerin iskelet kalıntılarına daha doğru bir şekilde uygulanması açısından yardımcı olabilir. Bu çalışmada 32 birey üzerinde yapılan bilateral asimetri analizi ile incelenen dört metrik ölçümün hiçbirinde sağ ve sol tibia arasında istatistiksel olarak anlamlı bir farklılık bulunmamıştır. Bulunan bu sonuçlar literatürde yapılmış daha önceki bazı araştırmalarla da uyumludur (Kranioti ve Apostol, 2015; Ugochukwu vd., 2016; Bridge vd., 2020). Bu araştırmalara göre de, her ne kadar tibiada sağ ve sol taraflar arasinda bir bilateral asimetri durumu söz konusu olsa da, bu farkl1lik istatistiksel olarak anlamlı değildir.

$\mathrm{Bu}$ çalş̧malar sonucunda gelinen nokta, cinsiyet ve boy uzunluğu tahmini için popülasyonlara özgü modeller oluşturulurken, bu formüllerin tarafa özel olarak oluşturulup oluşturulmaması durumudur. Bu sebeple, bilateral asimetrinin düzeyinin belirlenmesi, sol ve sağ tibia ölçümleri için oluşturulacak diskriminant fonksiyonlarının cinsiyet ve boy uzunluğu tahmini için kullanırken, her iki tarafa özgü denklemler oluşturulması ya da tek taraflı denklemler oluşturulması için önemlidir. Ancak, tarafa özel modellerin de kendi içerisinde problemleri mevcuttur. Örneğin, bu şekilde hazırlanan diskriminant formüllerinde gerekli formül kullanılmadan önce kemiğin hangi tarafa ait olduğunun belirlenmesi 
gerekmektedir. Malesef, her durumda biyolojik profili çıarılmak istenen iskeletlerin ve kemiklerin bir bütün halinde bulunamaması, bu şekilde hazırlanmış formüllerin kullanımına sınırlılık getirmektedir.

\section{Sonuç}

Tüm bu çalışmalar göstermiştir ki, bilateral asimetrinin alt ekstremitelerde, özellikle de tibiada geçerliliği tartışmalıdır ve bu mevcut bilateral asimetrinin cinsiyet, yaş, boy uzunluğu formül ve modellerinde hesaba katılıp katılmamasıyla ilgili farklıgörüşler mevcuttur. Bu sebeple, bu çalışmada Türk popülasyonuna ait 32 bireyin 3B tibia görüntülerinden bilateral asimetri düzeyi araştırılmıştır. Kullanılan dört değişkenin sağ ve sol değerleri arasında belirli bir seviyede asimetri gözlense de taraflar arasında istatistiksel olarak anlamlı bir fark bulunmamıștır. $\mathrm{Bu}$ sebeple, bu araştırma sonucunda kullanılan 32 bireyden alınan hiçbir ölçümde bilateral asimetri istatiksel olarak anlamlı bir fark göstermediğinden, tibia kemiğinin hangi tarafa ait olduğunun belirlenemediği durumlarda, tek bir tarafa ait denklemlerin ve modellerin uygulanmasinın uygun olacağı düşünülmektedir. Bununla birlikte, insanların iskelet düzeyinde küçük değişiklikler gösterdiği kabul edilmiştir (Dangerfield, 2005) ve bu çalışmanın sonuçları da bunu desteklemektedir. Bu sebeple, biyolojik profil oluşturmak için yeni denklem ve modeller geliştirilirken bilateral asimetri düzeyi hesaba katılarak her iki taraf için ayrı yöntemlerin oluşturulması, ayrıca vaka çalışmalarında eğer taraf tanımlanabiliyorsa o tarafa özgü modellerin kullanılması daha sağlıklı sonuçlar alınmasına yardımcı olabilir. Başka bir alternatif olarak da, iskelet kalıntılarını ayırmaya çalışırken veya biyolojik profil parametlerinden birini tanımlamak için yöntem seçerken daha az asimetri sergileyen değişkenlerin kullanılması öncelikli olarak tercih edilebilir. Tabii ki, iskeletin korunma durumuna ve hangi kemiklerin çalışmak için uygun durumda olacağına göre böyle bir tercihin yapılıp yapılamayacağı değişebilecektir. Ancak olası bilateral asimetri varlığının tanımlanması ya da çalışılacak değişkenlerin asimetri gösterme olasıllğına göre tercih edilmesi, kullanılan yöntemin doğruluğunu ve güvenilirliğini etkileyeceğini unutmamak gerekir.

$\mathrm{Bu}$ çalışmada bulunan bulgular sadece burada kullanılan popülasyon örneği ve incelenen spesifik metrik ölçümler için geçerli olmakla birlikte, Türk popülasyonuna ait yetişkin bireylerde sağ ve sol tibia kemiğinde bilateral asimetri düzeyi hakkında hem klinik hem de antropolojik çalışmalar için önemli ipuçları sağlamaktadır. Ayrıca, çalışmada tibia kemiklerinin sağ ve sol taraflarında belirli derecelerde asimetri gözlenmesine rağmen istatistiksel olarak anlamlı bir fark olmamasının sebebi, karşılaştırılan örneklem sayısının az olması olabilir. Bu sebeple, farklı yaş gruplarının eklenerek örneklem sayısı artırılarak yapılacak ileri bir çalışmanın Türk popülasyonu için tibia kemiğindeki bilateral asimetri düzeyi hakkında daha ayrıntılı yorumlar yapmamıza yardımcı olacaktır.

\section{Kaynakça}

Auerbach, B. M., ve Raxter, M. H. (2008). Patterns of clavicular bilateral asymmetry in relation to the humerus: variation among humans. Journal of Human Evolution, 54(5), 663-674. https://doi.org/10.1016/j.jhevol.2007.10.002

Auerbach, B. M., ve Ruff, C. B. (2006). Limb bone bilateral asymmetry: Variability and commonality among modern humans. Journal of Human Evolution, 50(2), 203-218.https:// doi.org/10.1016/j.jhevol.2005.09.004

Barnes, A. E., Case, D. T., Burnett, S. E., ve Mahakkanukrauh, P. (2019). Sex estimation from the carpal bones in a Thai population. Australian Journal of Forensic Sciences, 1-16. https://doi.org/10.1080/00450618.2019.1620856

Bridge, A. L., Oxenham, M.F., ve Miszkiewicz, J. J. (2020). Estimating stature using human forearm and leg anthropometric data in an Australian female sample. Australian Journal of Forensic Sciences, 52(1), 83-95. https://doi.org/10.1080/00450618.201 $\underline{8.1484162}$

Buikstra, J. E., ve Ubelaker, D. (1994). Standards for data collection from buman skeletal remains (Vol. 44). Arkansas Archeological Survey Research Series.

Chovalopoulou, M. E., Papageorgopoulou, C., ve Bertsatos, A. (2017). Cranium asymmetry in a modern Greek population sample of known age and sex. International Journal of Legal Medicine, 131(3), 803-812. https://doi.org/10.1007/s00414-016$1430-4$

Dangerfield, P. H. (2005). Asymmetry and growth. S. Ulijaszek ve C. G. Mascie-Taylor (Ed.) içinde, Anthropometry: the individual and the population (s. 227). Cambridge University.

Dirkmaat, D. (2014). A Companion to Forensic Anthropology. John Wiley \& Sons.

Eckhoff, D. G., Jacofsky, D. J., Springer, B. D., Dunbar, M., Cherian, J. J., Elmallah, R. K., ve Greene, K. A. (2016). Bilateral symmetrical comparison of femoral and tibial anatomic features. Journal of Arthroplasty, 31(5), 1083-1090. https://doi. org/10.1016/j.arth.2015.11.021

Fatah, A., ElHak, E., Shirley, N. R., Mahfouz, M. R., ve Auerbach, B. M. (2012). A three-dimensional analysis of bilateral directional asymmetry in the human clavicle. American Journal of Physical Anthropology, 149(4), 547-559. https://doi. org/10.1002/ajpa.22156

Garson, J. G. (1879). Inequality in length of the lower limbs. Journal of Anatomy and Physiology, 13(4), 502-507.

Gonzaléz-Reimers, E., Velasco-Vázquez, J., Arnay-De-La-Rosa, M., ve Santolaria-Fernández, F. (2000). Sex determination by discriminant function analysis of the right tibia in the prehispanic population of the Canary Islands. Forensic Science International, 108(3), 165-172. $\underline{\text { https://doi.org/10.1016/ }}$ $\underline{\text { S0379-0738(99)00205-4 }}$ 
Gülhan, Ö. (2018). Pelvis'ten radyolojik yöntemler ile cinsiyet tayini: Türkiye örneklemi. Antropoloji, (36), 53-69. https://doi. org/10.1501/antro 0000000358

Hildebrandt, E. M., Manske, S. L., Hanley, D. A., ve Boyd, S. K. (2016). Bilateral asymmetry of radius and tibia bone macroarchitecture and microarchitecture: A high-resolution peripheral quantitative computed tomography study. Journal of Clinical Densitometry, 19(2), 250-254. https://doi. org/10.1016/j.jocd.2015.02.005

Hishmat, A. M., Michiue, T., Sogawa, N., Oritani, S., Ishikawa, T., Fawzy, I. A., ve Maeda, H. (2015). Virtual CT morphometry of lower limb long bones for estimation of the sex and stature using postmortem Japanese adult data in forensic identification. International Journal of Legal Medicine, 129(5), 1173-1182. https://doi.org/10.1007/s00414-015-1228-9

Holland, T. D. (1991). Sex assessment using the proximal tibia. American Journal of Physical Anthropology, 85(2), 221-227. https://doi.org/10.1002/ajpa.1330850210

Howley, D., Howley, P., ve Oxenham, M. F. (2018). Estimation of sex and stature using anthropometry of the upper extremity in an Australian population. Forensic Science International, 287, 220. e1-220.e10. https://doi.org/10.1016/j.forsciint.2018.03.017

İşcan, M. Y. (2005). Forensic anthropology of sex and body size. Forensic Science International, 147(2-3), 107-112. https://doi. org/10.1016/i.forsciint.2004.09.069

Jantz, R. L., Hunt, D. R., ve Meadows, L. (1995). The measure and mismeasure of the tibia: implications for stature estimation. Journal of Forensic Sciences, 40(5), 758-761. https://doi. org/10.1520/JFS15379J

Jaskulska, E. (2009). Skeletal bilateral asymmetry in a medieval population from Deir an-Naqlun (Nekloni), Egypt. Bioarchaeology of the Near East, 3, 17-26.

Kanchan, T., Kumar, T. S. M., Kumar, G. P., ve Yoganarasimha, K. (2008). Skeletal asymmetry. Journal of Forensic and Legal Medicine, 15(3), 177-179. https://doi.org/10.1016/i.jflm.2007.05.009

Kieser, J. A., Moggi-Cecchi, J., ve Groeneveld, H. T. (1992). Sex allocation of skeletal material by analysis of the proximal tibia. Forensic Science International, 56(1), 29-36. https://doi. org/10.1016/0379-0738(92)90143-K

Kirchengast, S. (2017). Directional and fluctuating asymmetry among !Kung San and Kavango people of Northern Namibia: The impact of sex and subsistence patterns. American Journal of Human Biology, 29(2), e22921. https://doi.org/10.1002/ ajhb.22921

Koo, T. K., ve Li, M. Y. (2016). A guideline of selecting and reporting intraclass correlation coefficients for reliability research. Journal of Chiropractic Medicine, 15(2), 155-163. https://doi.org/10.1016/j.jcm.2016.02.012

Kranioti, E. F., ve Apostol, M. A. (2015). Sexual dimorphism of the tibia in contemporary Greeks, Italians, and Spanish: Forensic implications. International Journal of Legal Medicine, 129(2), 357363. https://doi.org/10.1007/s00414-014-1045-6

Krishan, K., Kanchan, T., ve DiMaggio, J. A. (2010). A study of limb asymmetry and its effect on estimation of stature in forensic case work. Forensic Science International, 200(1-3), 181. e1-181.e5. https://doi.org/10.1016/j.forsciint.2010.04.015

Kubicka, A. M., Lubiatowski, P., Długosz, J. D., Romanowski, L., ve Piontek, J. (2016). Directional asymmetry of upper limbs in a medieval population from Poland: A combination of linear and geometric morphometrics. American Journal of Human Biology, 28(6), 817-824. https://doi.org/10.1002/ajhb.22873

Kujanová, M., Bigoni, L., Velemínská, J., ve Velemínský, P. (2008). Limb bones asymmetry and stress in medieval and recent populations of Central Europe. International Journal of Osteoarchaeology, 18(5), 476-491. https://doi.org/10.1002/ oa. 958

Kurki, H. K. (2017). Bilateral asymmetry in the human pelvis. The Anatomical Record, 300(4), 653-665. https://doi.org/10.1002/ ar.23546

Latimer, H. B., ve Lowrance, E. W. (1965). Bilateral asymmetry in weight and in length of human bones. The Anatomical Record, 152(2), 217-224. https://doi.org/10.1002/ar.1091520213

Lesciotto, K. M. (2015). The Impact of Daubert on the admissibility of forensic anthropology expert testimony. Journal of Forensic Sciences, 60(3), 549-555. https://doi.org/10.1111/1556$\underline{4029.12740}$

Lottering, N., MacGregor, D. M., Barry, M. D., Reynolds, M. S., ve Gregory, L. S. (2014). Introducing standardized protocols for anthropological measurement of virtual subadult crania using computed tomography. Journal of Forensic Radiology and Imaging, 2(1), 34-38. https://doi.org/10.1016/j.jofri.2013.11.005

Lottering, N., MacGregor, D. M., Meredith, M., Alston, C. L., ve Gregory, L. S. (2013). Evaluation of the suchey-brooks method of age estimation in an Australian subpopulation using computed tomography of the pubic symphyseal surface. American Journal of Physical Anthropology, 150(3), 386399. https://doi.org/10.1002/ajpa.22213

Lyman, R. L.(2006).Identifying bilateral pairs of deer (Odocoileus sp.) bones: How symmetrical is symmetrical enough? Journal of Archaeological Science, 33(9),1256-1265. https://doi. org/10.1016/i.jas.2006.01.002

Mastrangelo, P., De Luca, S., Alemán, I., ve Botella, M. C. (2011). Sex assessment from the carpals bones: Discriminant function analysis in a 20th century Spanish sample. Forensic Science International, 206(1-3), 216.e1-216.e10. https://doi. org/10.1016/j.forsciint.2011.01.007

Mastrangelo, P., De Luca, S., ve Sánchez-Mejorada, G. (2011). Sex assessment from carpals bones: Discriminant function analysis in a contemporary Mexican sample. Forensic Science International, 209(1-3), 196.e1-196.e15. https://doi. org/10.1016/j.forsciint.2011.04.019

McGrew, W. C., ve Marchant, L. F. (1997). On the other hand: current issues in and meta-analysis of the behavioral laterality of hand function in nonhuman primates. American Journal of Physical Anthropology, 104(S25), 201-232. https://doi.org/10.1002/ (SICI) 1096-8644(1997)25+<201::AID-AJPA8>3.0.CO;2-6

Mongle, C. S., Wallace, I. J., ve Grine, F. E. (2015). Cross-sectional structural variation relative to midshaft along hominine 
diaphyses. II. the hind limb. American Journal of Physical Anthropology, 158(3), 398-407. https://doi.org/10.1002/ ajpa. 22802

Nandi, M. E. ., Olabiyi, O. A. ., Okubike, E. A., ve Iheaza, E. C. . (2018). A study of bilateral asymmetry of upper extremities and its effects on stature reconstruction amongst Nigerians. Arab Journal of Forensic Sciences \& Forensic Medicine (AJFSFM), 1(8), 978-988. https://doi.org/10.26735/16586794.2018.023

Nikita, E., ve Lahr, M. M. (2011). Simple algorithms for the estimation of the initial number of individuals in commingled skeletal remains. American Journal of Physical Anthropology, 146(4), 629-636. https://doi.org/10.1002/ajpa.21624

Pearson, K., ve Bell, J. (1919). A study of the long bones of the English skeleton. Cambridge University Press.

Pierre, M. A., Zurakowski, D., Nazarian, A., Hauser-Kara, D. A., ve Snyder, B. D. (2010). Assessment of the bilateral asymmetry of human femurs based on physical, densitometric, and structural rigidity characteristics. Journal of Biomechanics, 43(11), 2228-2236. https://doi.org/10.1016/j.jbiomech.2010.02.032

Plochocki, J. (2004). Bilateral variation in limb articular surface dimensions. American Journal of Human Biology, 16(3), 328-333. https://doi.org/10.1002/ajhb.20023

Priya, E. (2017). Methods of skeletal age estimation used by forensic anthropologists in adults: A review. Foresic Research \& Criminology International Journal, 4(2). https://doi. org/10.15406/frcii.2017.04.00104

Robinson, M. S., ve Bidmos, M. A. (2011). An assessment of the accuracy of discriminant function equations for sex determination of the femur and tibia from a South African population. Forensic Science International, 206(1), 212. e1-212. e5. https://doi.org/10.1016/j.forsciint.2010.12.009

Ruff, C. B., ve Jones, H. H. (1981). Bilateral asymmetry in cortical bone of the humerus and tibia: Sex and age factors. Human Biology, 53(1), 69-86.

Schaeffer, A. A. (1928). Spiral movement in man. Journal of Morphology, 45(1), 293-398. https://doi.org/10.1002/ imor.1050450110

Sládek, V., Berner, M., Holt, B., Niskanen, M., ve Ruff, C. B. (2017). Past human manipulative behavior in the European Holocene as assessed through upper limb asymmetry. C. B. Ruff (Ed.) içinde, Skeletal variation and adaptation in Europeans: Upper Paleolithic to the twentieth century (s. 163-208). John Wiley \& Sons, Inc. https://doi.org/10.1002/9781118628430.ch7

Šlaus, M., Bedić, Ž., Strinović, D., ve Petrovečki, V. (2013). Sex determination by discriminant function analysis of the tibia for contemporary Croats. Forensic Science International, 226(1-3), 302.e1-302.e4. https://doi.org/10.1016/j. forsciint.2013.01.025

Steele, J., ve Mays, S. (1995). Handedness and directional asymmetry in the long bones of the human upper limb. International Journal of Osteoarchaeology, 5(1), 39-49. https://doi.org/10.1002/ $\underline{\mathrm{Oa} .1390050105}$

Steyn, M, Becker, P., EN, L., Scholtz, Y., ve J., M. (2012). An assessment of the repeatability of pubic and ischial measurements. Forensic Science International, 214(1-3), 210.e1210.e4. https://doi.org/10.1016/i.forsciint.2011.07.049

Steyn, M., ve İşcan, M. Y. (1997). Sex determination from the femur and tibia in South African whites. Forensic Science International, 90(1), 111-119. https://doi.org/10.1016/S03790738(97)00156-4

Stirland, A. (1993). Asymmetry and activity-related change in the male humerus. International Journal of Osteoarchaeology, 3(2), 105113. https://doi.org/10.1002/oa.1390030207

Stomfai, S., Ahrens, W., Bammann, K., Kovács, E., Mårild, S., Michels, N., ve Molnár, D. (2011). Intra- and inter-observer reliability in anthropometric measurements in children. International Journal of Obesity, (35), S45-S51. https://doi. org/10.1038/ijo.2011.34

Stoyanova, D. K., Algee-Hewitt, B. F. B., Kim, J., ve Slice, D. E. (2019). A study on the asymmetry of the human left and right pubic symphyseal surfaces using high-definition data capture and computational shape methods. Journal of Forensic Sciences, 64(2), 494-501. https://doi.org/10.1111/1556-4029.13871

Sulzmann, C. E., Buckberry, J. L., ve Pastor, R. F. (2008). The utility of carpals for sex assessment: A preliminary study. American Journal of Physical Anthropology, 135(3), 252-262. https://doi. org/10.1002/ajpa.20738

Tersigni-Tarrant, M. A., ve Shirley, N. R. (2013). Forensic anthropology: An introduction. CRC Press.

Torimitsu, S., Makino, Y., Saitoh, H., Sakuma,A., Yajima, D., Inokuchi, G., Motomura, A., ve Iwase, H. (2015) .Morphometric analysis of sex differences in contemporary Japanese pelves using multidetector computed tomography. Forensic Science International, 257(530),530.e1-530.e7. https:// doi.org/10.1016/i.forsciint.2015.10.018

Trinkaus, E., Churchill, S. E., ve Ruff, C. B. (1994). Postcranial robusticity in Homo . II: Humeral bilateral asymmetry and bone plasticity. American Journal of Physical Anthropology, 93(1), 1-34. https://doi.org/10.1002/ajpa.1330930102

Trotter, M., ve Gleser, G. C. (1952). Estimation of stature from long bones of American Whites and Negroes. American Journal of Physical Anthropology, 10(4), 463-514. https://doi. org/10.1002/ajpa.1330100407

Ugochukwu, E., Ugbem, L., Ijomone, O., ve Ebi, O. (2016). Estimation of maximum tibia length from its measured anthropometric parameters in a Nigerian population. Journal of Forensic Science and Medicine, 2(4), 222-228. https://doi. org/10.4103/2349-5014.197928

Waidhofer, M., ve Kirchengast, S. (2015). Sexual dimorphism in directional asymmetry of the upper limb bones among KhoeSan skeletons. Homo - Journal of Comparative Human Biology, 66(6), 508-519. https://doi.org/10.1016/j.jchb.2015.08.001

Warren, E. (1897). An investigation on the variability of the human skeleton with especial reference to the Naqada race, discovered by Professor Flinders Petrie in his explorations in Egypt. Philosophical Transactions of the Royal Society of London B: Biological Sciences, 61(369-377), 398-401. https://doi. 
org/10.1098/rspl.1897.0051

Waxenbaum, E. B., ve Sirak, K. A. (2016). Developmental patterns of bilateral asymmetry in ancestral Puebloans. American Journal of Human Biology, 28(3), 421-430. https://doi.org/10.1002/ ajhb.22804

Weinberg, S. M., Scott, N. M., Neiswanger, K., ve Marazita, M. L. (2005). Intraobserver error associated with measurements of the hand. American Journal of Human Biology, 17(3), 368-371. https://doi.org/10.1002/ajhb.20129

\section{(c) 0 \\ BY NC 2020. Telif haklar1 yazar(lar)a aittir}

Bu makale Creative Commons Attf-GayriTicari 4.0 Uluslararas1 (CC BY-NC 4.0) lisansının hüküm ve şartları altında yayımlanan açık erişimli bir makaledir. 